\title{
LA-UR-21-21624
}

Approved for public release; distribution is unlimited.

Title:

Author(s):

Intended for: Web
2021 Engineers Week Penny Bridge Challenge Video

Redman, Chelsea Dalelyn

Strong, Melvin Henry

Issued:

2021-02-19 
Disclaimer:

Los Alamos National Laboratory, an affirmative action/equal opportunity employer, is operated by Triad National Security, LLC for the National Nuclear Security Administration of U.S. Department of Energy under contract 89233218CNA000001. By approving this article, the publisher recognizes that the U.S. Government retains nonexclusive, royalty-free license to publish or reproduce the published form of this contribution, or to allow others to do so, for U.S. Government purposes. Los Alamos National Laboratory requests that the publisher identify this article as work performed under the auspices of the U.S. Department of Energy. Los Alamos National Laboratory strongly supports academic freedom and a researcher's right to publish; as an institution, however, the Laboratory does not endorse the viewpoint of a publication or guarantee its technical correctness. 


\section{Engineers Week Penny Bridge Challenge Video}

This is the second video in a series of four videos that have been prepared by the Bradbury Science Museum for the celebration of Engineers Week. The video is 3 minutes and 24 seconds in length. It presents the materials needed and the rules/constraints for students to participate in the penny bridge engineering challenge. 